\section{5 pan-bacterial PCR can accurately identify patients with ventilator-associated pneumonia}

Ventilator-associated pneumonia (VAP) remains a challenge to intensive care units, with secure diagnosis relying on microbiological cultures that take up to 72 hours to provide a result. We sought to derive and validate a novel, real-time $16 S$ rRNA gene PCR for rapid exclusion of VAP. Bronchoalveolar lavage (BAL) was obtained from two independent cohorts of patients with suspected VAP. Patients were recruited in a 2-centre derivation cohort and a 12-centre confirmation cohort. Confirmed VAP was defined as growth of $>10^{4}$ colony forming units $/ \mathrm{ml}$ on semiquantitative culture and compared with a 16S PCR assay. Samples were tested from 67 patients in the derivation cohort, $10(15 \%)$ of whom had confirmed VAP. Using cycles to cross threshold $\left(C_{t}\right)$ values as the result of the 16S PCR test, the area under the receiver operating characteristic (ROC) curve (AUROC) was 0.94 (95\% Cl 0.86 to 1.0, $p<0.0001)$. Samples from 92 patients were available from the confirmation cohort, 26 (28\%) of whom had confirmed VAP. The AUROC for $C_{t}$ in this cohort was $0.89(95 \% \mathrm{Cl}$ 0.83 to $0.95, p<0.0001)$. This study has derived and assessed the diagnostic accuracy of a novel application for 16S PCR. This suggests that $16 S$ PCR in BAL could be used as a rapid test in suspected VAP and may allow better stewardship of antibiotics.

Trial registration VAPRAPID trial ref NCT01972425.

\section{INTRODUCTION}

Ventilator-associated pneumonia (VAP) remains a significant problem in intensive care units (ICUs) ${ }^{1}$ and despite reductions in reported VAP rates antibiotic use remains high. ${ }^{2}$ The most common indication for antibiotic use remains suspected respiratory infections. ${ }^{3}$ VAP is associated with significant morbidity and mortality ${ }^{1}$ especially when antibiotics are delayed or are inadequate. ${ }^{4}$ However, due to the various conditions that can mimic VAP, commonly only $30 \%$ of those suspected of having VAP subsequently have this diagnosis confirmed. ${ }^{4}$ The delays in obtaining results from conventional microbiological cultures lead to empirical use of broadspectrum antibiotics of which a significant proportion is later deemed unnecessary. The excessive use of antibiotics is associated with increased antimicrobial resistance $^{5}$ and mortality. ${ }^{6}$

The ubiquitous presence of a $16 \mathrm{~S}$ ribosomal RNA gene in bacteria offers the possibility of detecting a wide range of bacteria in a single PCR. ${ }^{7}$ Amplification of the $16 \mathrm{~S}$ rRNA gene in a PCR assay results in amplification of all bacteria in a sample. Therefore, this offers potential as a screening test for suspected VAP. The aim of this study was to derive and validate a real-time $16 \mathrm{~S}$ PCR assay for diagnosing confirmed VAP.

\section{METHODS}

Samples from two previously described 89 cohorts of adult patients with clinically suspected VAP recruited from UK ICUs formed the derivation ${ }^{8}$ and confirmation ${ }^{9}$ cohorts respectively. Briefly, patients were recruited if they met criteria for suspected VAP, namely new or worsening chest X-ray changes following at least 48 hours of ventilation, accompanied by two or more of: temperature $>38^{\circ} \mathrm{C}$; white cell count $>11 \times 10^{9} / \mathrm{L} ;$ or mucopurulent sputum. In the derivation cohort patients were excluded if they had received new antibiotics within the 3 days prior to recruitment; ${ }^{8}$ no such exclusion was applied to the confirmation cohort. ${ }^{9}$ Patients underwent protocolised bronchoscopic bronchoalveolar lavage (BAL) ${ }^{8} \quad 9$ and an aliquot of BAL fluid was processed using a semiquantitative culture method. This culture was used as our reference diagnostic standard, with growth at $>10^{4}$ colony forming units $/ \mathrm{mL}(\mathrm{CFU} / \mathrm{mL})$ of BAL fluid being defined as 'VAP positive' and growth $<10^{4} \mathrm{CFU} / \mathrm{mL}$ as 'VAP negative', these cut-offs being in line with established standards. ${ }^{14}$

Full details of sample processing are described in the online supplementary section. Briefly, the fraction of lavage not used for conventional culture was centrifuged to produce a cell-free supernatant, followed by nucleic acid extraction. The 16S PCR assays are described below; assay 1 and assay 2 were conducted in geographically separate laboratories.

\section{Real-time 16S PCR assay 1}

The primer and probe sequences targeting the16S rRNA gene have been described previously. ${ }^{10}$ The probe contained a carboxyfluorescein (FAM) label on the $5^{\prime}$ end with a Black Hole Quencher 1 (BHQ1) on the $3^{\prime}$ end. Primers and probe were synthesised by Eurogentec (Liège, Belgium). The final 16S PCR reaction mix contained 1.25U HotStarTaq polymerase and $1 \times$ reaction buffer (Qiagen, Manchester, UK), $4 \mu \mathrm{M} \mathrm{MgCl} 2,0.2 \mathrm{mM}$ deoxynucleotide mix (dNTP), $0.25 \mu \mathrm{M}$ primer $27-\mathrm{F}, 0.75 \mu \mathrm{M}$ primer $16 \mathrm{~S} 1 \mathrm{RR}-\mathrm{B}$, $0.3 \mu \mathrm{M}$ probe $514-\mathrm{S}$, nuclease-free water (Promega, Southampton, UK) and $10 \mu \mathrm{L}$ nucleic acid extract to a final volume of $25 \mu \mathrm{L}$. Real-time PCR was carried out on the ABI 7500 instrument (Applied Biosystems, Life Technologies, Paisley, UK). This assay was used for samples from the derivation cohort, to establish proof in principle of the diagnostic utility of this approach, and was also used for samples from the confirmation cohort.

\section{Real-time 16S PCR assay 2}

The primer and hybridisation probe sequences targeting the $16 \mathrm{~S}$ rRNA gene have been described previously. ${ }^{11}$ The hybridisation probe contained a FAM label on the $5^{\prime}$ end with a BHQ1 on the $3^{\prime}$ end. Primers and hybridisation probe were synthesised by Sigma Genosys (Sigma-Aldrich, Ebersberg, Germany).

The final 16S PCR reaction mix contained 1X Platinum uracil DNA glycosylase Mastermix (Life Technologies, Paisley, UK), $0.2 \mu \mathrm{M}$ bovine serum albumin (Sigma, Dorset, UK), a total of $4 \mathrm{mmol} / \mathrm{L}$ $\mathrm{MgCl}_{2}, \quad 0.4 \mu \mathrm{M}$ forward and reverse primers, $0.1 \mu \mathrm{M}$ hybridisation probe, nuclease-free water (Promega, Southampton, UK) and $2 \mu \mathrm{L}$ of target template for a final reaction volume of $10 \mu \mathrm{L}$. Real-time qPCR was carried out on a Light Cycler 480 instrument (Roche, Indianapolis, Indiana, USA). This assay was used on samples from the confirmation cohort only.

For the purposes of analysis, the metric was cycles to cross threshold $\left(C_{t}\right)$ as a measure of $16 \mathrm{~s}$ rRNA gene load and hence bacterial burden. A higher bacterial load will result in a lower time to cross threshold, that is, a lower $C_{t}$ value. Details of statistical analyses used can be found in the online supplementary methods section. Both studies had approvals from relevant research ethics committees; full details are in the online supplementary section.

\section{RESULTS}

In the derivation cohort, samples from 67 patients were available, of whom $10(15 \%)$ had 'microbiologically confirmed VAP'. In the 'confirmation' cohort samples from 92 patients were available for analysis; 26 (28\%) met the culture criteria for 'microbiologically confirmed VAP'. The demographic details and organisms cultured are shown in the online supplementary section (see online supplementary tables S1 and S2).

16S PCR assay 1 demonstrated that patients with confirmed VAP had a higher bacterial burden, as signified by a lower $C_{t}$ value, than those without VAP (figure 1A). When evaluated for diagnostic ability by ROC curve, assay 1 demonstrated excellent 
Figure 1 Real-time 16S PCR results as expressed by cycles to cross threshold (Ct) for samples from patients. (A) $C_{t}$ values from assay 1 among derivation cohort patients with and without confirmed ventilator-associated pneumonia (VAP). $\mathrm{N}=67,57$ non-VAP and $10 \mathrm{VAP}$, error bars show median and IQR. **** $\mathrm{p}<0.0001$ by Mann-Whitney $U$ test. (B) $C_{t}$ values from assay 1 among confirmation cohort patients with and without confirmed VAP. $\mathrm{N}=92,66$ non-VAP and 26 VAP, error bars show median and IQR. **** $\mathrm{p}<0.0001$ by Mann-Whitney $\mathrm{U}$ test. (C) $\mathrm{Ct}$ values from assay 2 among confirmation cohort patients with and without confirmed VAP. $\mathrm{N}=92,66$ non-VAP and 26 VAP, error bars show median and IQR. ${ }^{* * *} \mathrm{p}<0.0001$ by Mann-Whitney U test.
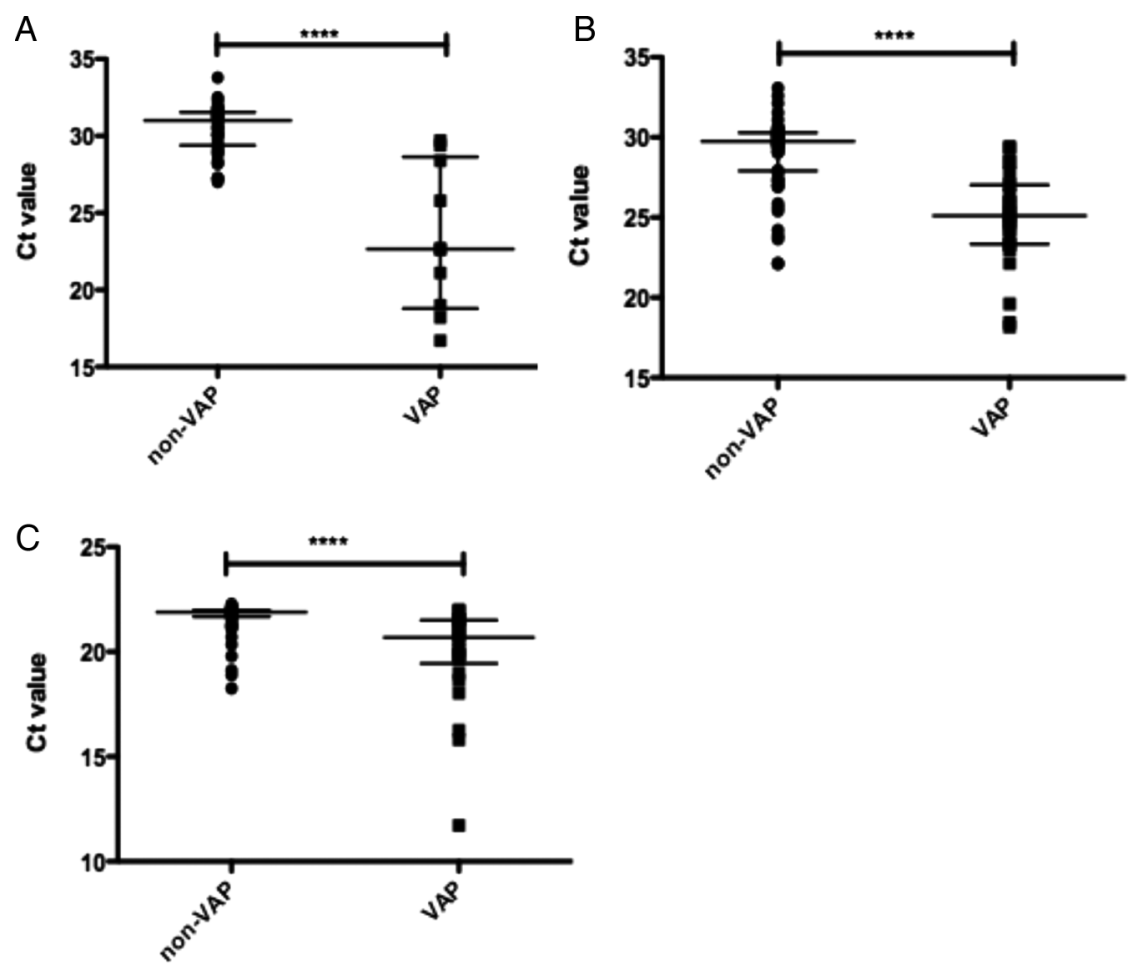

diagnostic ability (see table 1 and figure S1A) with an area under the ROC curve (AUROC) of 0.94 (95\% CI 0.86 to 1.00 ), sensitivity of $100 \%$ and specificity $72 \%$ at the most optimal cut-off.

In the confirmation cohort, patients with confirmed VAP had significantly lower $16 \mathrm{~S} \mathrm{C}_{t}$ values (figure $1 \mathrm{~B}$ ), and a similar diagnostic performance was demonstrated (table 1 and figure S1B), with sensitivity of $100 \%$ and specificity of $67 \%$ at the most optimal cut-off. The difference between the AUROC of the cohorts was not statistically significant $(\mathrm{p}=0.56)$.

Samples from the confirmation cohort were also tested using $16 \mathrm{~S}$ assay 2 . As seen in figure $1 \mathrm{C}$, although the absolute $C_{t}$ values differed between the two assays, the same relationship between VAP and non-VAP samples was observed. ROC analysis (table 1 and figure S1C) demonstrated good diagnostic ability (area under the curve $0.8495 \%$ CI 0.75 to 0.94 ) with sensitivity $89 \%$ and specificity $80 \%$ at the optimal cut-off. Although the point estimates of AUROC were higher for assay 1, the difference did not achieve statistical significance $(p=0.4)$. However if the assays are compared at maximal sensitivity (100\%), the specificity of assay 1 is significantly higher (table 1). Using the Youden Index to define optimal $\mathrm{C}_{t}$ value cut-offs on the ROC curve, a 'positive' result for $16 \mathrm{~S}$ would be a value below this cut-off (indicating high bacterial load) and a 'negative' result would be a value above this cut-off (indicating low bacterial load).

Table 1 Diagnostic performance of the two 165 assays

\begin{tabular}{|c|c|c|c|}
\hline Curve & Assay 1 derivation & $\begin{array}{l}\text { Assay } 1 \\
\text { confirmation }\end{array}$ & $\begin{array}{l}\text { Assay } 2 \\
\text { confirmation }\end{array}$ \\
\hline AUC ROC & $\begin{array}{l}0.94(0.86 \text { to } 1.0) \\
p<0.0001\end{array}$ & $\begin{array}{l}0.89(0.83 \text { to } 0.95) \\
p<0.0001\end{array}$ & $\begin{array}{l}0.84(0.75 \text { to } 0.94) \\
p<0.0001\end{array}$ \\
\hline Youden optimum cut-off (Ct) & 29.85 & 29.43 & 21.59 \\
\hline $\begin{array}{l}\text { Youden optimum sensitivity/specificity } \\
(95 \% \mathrm{Cl})\end{array}$ & $\begin{array}{l}100(69 \text { to } 100) / 72 \\
(58 \text { to } 83)\end{array}$ & $\begin{array}{l}100(87 \text { to } 99) / 67 \\
\text { (54 to } 78)\end{array}$ & $\begin{array}{l}89(70 \text { to } 98) / 80 \\
(69 \text { to } 89)\end{array}$ \\
\hline Maximum sensitivity optimum cut-off (Ct) & 29.85 & 29.43 & 22.02 \\
\hline Maximum sensitivity/specificity (95\% Cls) & $\begin{array}{l}100(69 \text { to } 100) / 72 \\
(58 \text { to } 83)\end{array}$ & $\begin{array}{l}100(87 \text { to } 100) / 67 \\
\text { (54 to } 78)\end{array}$ & $\begin{array}{l}100(86 \text { to } 100) / 15 \\
(8 \text { to } 26)\end{array}$ \\
\hline
\end{tabular}

(ROC curves displayed in online supplementary figure S1).

As avoiding false-negative results is important in rapid tests for VAP, we also report the specificity at maximum $(100 \%)$ sensitivity.

AUC, area under the curve; $C_{t}$, cycles to crossing threshold; VAP, ventilator-associated pneumonia.

In the derivation cohort, $35(52 \%)$ patients were receiving antibiotics on the day of recruitment. In the confirmation cohort, 69 (75\%) were receiving antibiotics and $14(15 \%)$ had undergone a change of antibiotics within the past 3 days. Receipt of antibiotics and recent change in antibiotics were not associated with changes in $16 \mathrm{~S}_{\mathrm{t}}$ values (see online supplementary results and table $\mathrm{S} 3$ ).

Figure S2 shows the relationship between $C_{t}$ values for the two $16 \mathrm{~S}$ assays, demonstrating a non-linear association.

\section{DISCUSSION}

To our knowledge, this is the first report of the use of real-time 16S PCR for diagnosing VAP. Although 16S rRNA gene sequencing has been used to explore the microbiome of ventilated patients, data on its diagnostic potential have been absent. In deriving and confirming a test, with a high agreement in test performance between the two cohorts, we demonstrate clear potential for the clinical utility of this test. Turnaround time is 4-6 hours; therefore, this test could impact on antibiotic use, which may otherwise only be rationalised following the results of conventional cultures at $48-72$ hours.

This study has a number of strengths. First, we were able to perform derivation and confirmation in two distinct cohorts, with confirmation in a cohort recruited from a diverse group of 12 ICUs. The results are therefore likely to be widely applicable; 
indeed, the microbiological spectrum found is similar to reports from other countries. ${ }^{4}$ Second, by using consistent diagnostic procedures within each cohort, we avoided some of the problems which occur with the diagnosis of VAP. ${ }^{14}$ Our rate of microbiologically confirmed VAP in both cohorts $(23 \%)$ is at the lower end of the reported range ${ }^{4}$ but not out of keeping with other reports and we believe this may, in part, reflect the use of highly standardised BAL protocols.

A disadvantage of this study is that samples were obtained bronchoscopically, requiring resource and exposing patients to a small but definite risk, and the applicability of this test to other sample types cannot be inferred. The assays we describe here are also limited to bacterial detection. The differences between the two assays tested, and the use of stored samples, highlight the need for external prospective validation before this measure could be implemented in routine clinical practice. Further refinements of assays may also improve diagnostic performance. The reference standard of growth of organisms on conventional culture, remains imperfect, and indeed may well be influenced by intercurrent antibiotics generally, and recent changes in antibiotics specifically. ${ }^{12}$ However this remains the established standard ${ }^{4}$ and is used routinely for clinical decision-making. As such, the $16 \mathrm{~S}$ assay described here can predict the results of a clinically relevant test, but within 6 hours rather than the 4872 hours taken for the conventional cultures.

In conclusion, we have derived and confirmed the diagnostic utility of a rapid laboratory test for VAP in a multicentre setting. We propose that this test has the potential to permit rapid decisions to direct antimicrobial therapy in patients with suspected VAP thus improving stewardship of antibiotics in the ICU.

\section{Andrew Conway Morris, ${ }^{1,2}$ Naomi Gadsby, ${ }^{3}$ James P McKenna, ${ }^{4}$ Thomas P Hellyer, ${ }^{5}$ Paul Dark, ${ }^{6,7}$ Suveer Singh, ${ }^{8}$ Timothy S Walsh, ${ }^{2}$ Danny F McAuley, ${ }^{9,10}$ Kate Templeton, ${ }^{3}$ A John Simpson, ${ }^{5}$ Ronan McMullan ${ }^{4,9}$}

${ }^{1}$ Division of Anaesthesia, Department of Medicine, University of Cambridge, Cambridge, UK

${ }^{2}$ Centre for Inflammation Research, University of Edinburgh, Edinburgh, UK

${ }^{3}$ Department of Clinical Microbiology, NHS Lothian, Edinburgh, UK

${ }^{4}$ Department of Microbiology, Belfast Health \& Social Care Trust, Belfast, UK

${ }^{5}$ Institute of Cellular Medicine, Newcastle University, Newcastle, UK

${ }^{6}$ Institute of Inflammation and Repair, University of Manchester, Manchester Academic Health Sciences Centre, Manchester, UK

${ }^{7}$ Intensive Care Unit, Salford Royal NHS Foundation Trust, Greater Manchester, UK

${ }^{8}$ Intensive Care Unit, Chelsea and Westminster Hospital, Imperial College London, London, UK
${ }^{9}$ Centre for Infection and Immunity, Queen's University Belfast, UK

${ }^{10}$ Intensive Care Unit, Royal Victoria Infirmary, Belfast, UK

Correspondence to Professor A John Simpson, Institute of Cellular Medicine, Medical School, Newcastle University, Framlington Place, 3rd Floor, William Leech Building, Newcastle upon Tyne NE2 4HH, UK; j.simpson@newcastle.ac.uk

Acknowledgements The authors thank VAP-RAPID collaborators, Niall H Anderson, Alistair I Roy, Simon V Baudouin, Stephen E Wright, Gavin D Perkins, Melinda Jeffels, Cecilia M O'Kane, Craig Spencer, Shondipon Laha, Nicole Robin, Savita Gossain, Kate Gould, Marie-Hélène Ruchaud-Sparagano, Jonathan Scott, Ian Dimmick, lan F Laurenson, Helen Walsh, Sarah Nutbrown, Charley Higham, Teresa Melody, Keith Couper, Jacqueline Baldwin, Alexandra Williams, Kylie Norrie, Julie Furneval, Tracey Evans, Heidi Dawson, Griania White, Lia McNamee, Leona Bannon, Laura Evans, Neil Young, Alasdair Hay, Ross Paterson, Stuart McLellan, Peter Kelleher, Berge Azadian, Masao Takata, Ildiko Kustos, John Cheesborough and Roland Koerne for their work in recruiting patients to the confirmation cohort. The authors also thank David Swann, Pam Ramsay, Gordon McNeil and Kallirroi Kefala for their work in recruiting patients into the derivation cohort. The authors also thank the patients and their relatives who allowed this research to take place.

Contributors ACM designed the study, obtained funding, recruited patients, analysed data and wrote the manuscript. NG performed the assays, analysed the data and revised the manuscript. JPMCK performed the assays, analysed the data and revised the manuscript. TPH designed the study, recruited patients and revised the manuscript. PD recruited patients, obtained samples and revised the manuscript. SS recruited patients, obtained samples and revised the manuscript. TSW recruited patients, obtained samples and revised the manuscript. DFM recruited patients, obtained samples and revised the manuscript. KT obtained the funding, designed and supervised the assays, and wrote the manuscript. AJS designed the study, obtained funding recruited patients and wrote the manuscript. RMcM obtained the funding, designed and supervised the assays, and wrote the manuscript.

Funding This study was funded by: the Northern Ireland Health and Social Care Research and Development division; the Hospital Infection Society; the Department of Health and Wellcome Trust through the Health Innovation Challenge Fund (HICF)(0510/ 078); and the Sir Jules Thorn Charitable Trust (03/JTA).

Competing interests $\mathrm{ACM}$ is a member of the advisory board of Serendex and is chief investigator on a diagnostics study jointly funded by Innovate UK and Becton Dickinson. KT has worked on evaluations of diagnostic systems for Becton Dickinson, Cepheid, Enigma, GenMark and SelexRM has received research grant income from Innovate UK for a diagnostics consortium (with Randox Diagnostics Ltd), investigator-led grant income from Pfizer Ltd and is a consultant/advisor for Gilead Sciences Ltd. All other authors declare no conflicts of interest.

\section{Patient consent Obtained}

Ethics approval Lothian Research Ethics Committee (REC), NRES North East REC, Scotland A REC.

Provenance and peer review Not commissioned; externally peer reviewed.

- Additional material is published online only. To view please visit the journal online (http://dx.doi.org/10. 1136/thoraxjnl-2016-209065).
(6)

OPEN ACCESS

Open Access This is an Open Access article distributed in accordance with the terms of the Creative Commons Attribution (CC BY 4.0) license, which permits others to distribute, remix, adapt and build upon this work, for commercial use, provided the original work is properly cited. See: http:/l creativecommons.org/licenses/by/4.0/

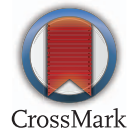

To cite Conway Morris A, Gadsby N, McKenna JP, et al. Thorax 2017;72:1046-1048.

Received 21 June 2016

Revised 10 September 2016

Accepted 1 October 2016

Published Online First 14 December 2016

Thorax 2017;72:1046-1048.

doi:10.1136/thoraxjnl-2016-209065

\section{REFERENCES}

1 Hunter JD. Ventilator associated pneumonia. BMJ 2012;344:e3325

2 Behnke $\mathrm{M}$, Hansen $\mathrm{S}$, Leistner $\mathrm{R}$, et al. Nosocomial infection and antibiotic use: a second national prevalence study in Germany. Dtsch Arztebl Int 2013;110:627-33.

3 Vincent JL, Rello J, Marshall J, et al. International study of the prevalence and outcomes of infection in intensive care units. JAMA 2009;302:2323-9.

4 Chastre J, Fagon JY. Ventilator-associated pneumonia. Am J Respir Crit Care Med 2002;165:867-903.

5 McGowan JE. Antimicrobial resistance in hospital organisms and its relation to antibiotic use. Clin Infect Dis 1983;5:1033-48.

6 Kett DH, Cano E, Quartin AA, et al. Implementation of guidelines for management of possible multidrug-resistant pneumonia in intensive care: an observational, multicentre cohort study. Lancet Infect Dis 2011:11:181-9.

7 Renvoisé A, Brossier F, Sougakoff W, et al. Broad-range PCR: past, present, or future of bacteriology?. Med Mal Infect 2013:43:322-30.

8 Conway Morris A, Kefala K, Wilkinson TS, et al. Diagnostic importance of pulmonary interleukinbeta and interleukin-8 in ventilator-associated pneumonia Thorax 2010;65:201-7.

9 Hellyer TP, Morris AC, McAuley DF, et al. Diagnostic accuracy of pulmonary host inflammatory mediators in the exclusion of ventilator-acquired pneumonia. Thorax 2015;70:41-7.

10 Schabereiter-Gurtner C, Nehr M, Apfalter $P$, et al. Evaluation of a protocol for molecular broad-range diagnosis of culture-negative bacterial infections in clinical routine diagnosis. J App/ Microbiol 2008:104:1228-37.

11 Yang S, Lin S, Kelen GD, et al. Quantitative multiprobe PCR assay for simultaneous detection and identification to species level of bacterial pathogens. J Clin Microbiol 2002:40:3449-54.

12 Montravers P, Fagon JY, Chastre J, et al. Follow-up protected specimen brushes to assess treatment in nosocomial pneumonia. Am Rev Respir Dis 1993;147:38-44. 